\title{
Empowerment through seamfulness: smart phones in everyday life
}

\author{
Louise Barkhuus • Valerie E. Polichar
}

Received: 7 May 2010/Accepted: 12 November 2010/Published online: 2 December 2010

(C) The Author(s) 2010. This article is published with open access at Springerlink.com

\begin{abstract}
In this paper, we describe research into use of multifunctional mobile phones by working adults and posit the device as a plausible realization of ubiquitous computing. We investigate how users actively adapt and adopt the different functions in smart phones to suit their needs and lifestyles. Through an interview and diary study, we discover how the smart phone is used in pragmatic and seamful ways, regardless of the interface of the specific phone selected or the particular features available. Users used phones in highly individual manners; mixed and adapted existing functions to meet their own priorities; added some functions and ignored others to create their own portfolio; and blended their use with the specifics of their everyday lives. While these data challenge some assumptions of human-computer interaction and ubiquitous computing, it also presents new research potential in terms of understanding how users take advantage of the multiple features in smart phone devices and how they utilize seamfulness in everyday smart phones practices.
\end{abstract}

Keywords Mobile phones - Cell phones - User study . Seamfulness $\cdot$ Multi-functionality

\footnotetext{
L. Barkhuus $(\square)$. V. E. Polichar

Department of Computer Science, University of California,

San Diego, 9500 Gilman Drive, Mail Stop 0404, La Jolla, CA 92093-0404, USA

e-mail: barkhuus@cs.ucsd.edu

V. E. Polichar

e-mail: vpolichar@ucsd.edu
}

\section{Introduction}

Truly mobile computing-lightweight, accessible on the go and wirelessly connected-has been a vital vision of ubiquitous computing, and the quest to refine its interface a primary goal of human factors research. Mobile devices have hence been both a research goal and a research tool. One mobile device in particular, the mobile phone, is now a key part of our everyday lives. As these phones have become "smarter"-incorporating multiple functions, including those of other devices such as the personal digital assistant (PDA), timer/alarm clock, GPS receiver/navigator, MP3 player, even laptop computer-they have approached the original vision of ultra-mobile interpersonal connectivity. Yet, in many ways, the multifunctional mobile phone conflicts with central historical notions of human-computer interaction-for example, that the design of the interface is critical to its use-and of ubiquitous computing (ubicomp), where the concept of distributed single-function computers, with sensors embedded into the environment, has been an influential early goal.

With the smart phone, computing is instead centralized in the palm of your hand. Voice and text communication, images and maps, information search, music enjoyment, game playing and even alarm clock services converge in a single unit. This defies Norman's argument that appliances, or single-function technologies, would prevail over complicated multifunctional devices [26]. Moreover, the inherently individual nature of a smart phone contrasts with Weiser's idea of tabs (computing by the inch), which would be available by large numbers and would often be shared [41]. Instead, each of us has a single 'pad' that is used for numerous purposes, and although smart phones have features relevant for sharing [15], they are ultimately personal devices. 
In fact, in our study of smart phones, our data suggest that the mobile phone fits better with Bell and Dourish's notion of "messiness" [5]. Although our users did not describe their experience as "messy", their adaptation of and to their devices provides strong empirical support for Bell and Dourish's description. The multifunctional phone appears to satisfy Bell and Dourish's designation of a ubicomp device as "highly present, visible, and branded, but perhaps still unremarkable." We suggest that the fact that the users did not perceive their devices as "messy" may simply indicate an underlying good match between a highly flexible design and the natural behavior of the users.

In this paper, we present an interview study of 21 users of 'smart phones' such as the iPhone, where 'smart phones' are defined as those mobile phones that incorporate multiple advanced functions (such as email and Web surfing) in addition to the traditional package of voice calling, voice mail and texting. We focus on users' integration of their phones into everyday life. Although a significant body of research has examined how the emergence of mobile phones has affected people's lives, few studies have looked at the more sophisticated smart phones. Scholars have attempted to make sense of use patterns, practices [13, 22, 29] and even convergence of communication across different technologies [24, 36]. However, research has yet to address the advanced constellation of services we find in modern phones-the role of the multifaceted functionality of smart phones.

While ubicomp research has used multifunctional phones extensively as a platform for testing specific applications [2, 8, 18, 28, 39], the detailed real-life use of multi-functionality has not yet been addressed. Even a special edition of Pervasive Computing on smart phones did not address off-the-shelf smart phone use, but merely looked at special features of smart phones (positioning of camera phones, health focused phones, etc.) [20]. Multiple functions enable users to do the same task in different ways and to blend functions in new and unique ways. Users can add functionality to their devices, and they can choose to ignore a function that is not relevant to them. Distributions such as Apple's AppStore provide an unprecedented ability to customize the functionality of a device to fit one's needs. Moreover, the richness of multi-functionality permits unprecedented integration into the immediate world of the user. If we want to understand and design for the world as it is, rather than the world as forecast, we must consider seriously how multi-functionality benefits users. In our study, we investigate users' everyday practices with smart phones and demonstrate how users actively adapt these devices in their daily life in what Rogers [34] describes as "engaged living."

This study seeks to underscore Bell and Dourish's suggestion that the dream of ubicomp has already come to pass [5], in the form of the mobile smart phone. We further provide evidence that the flexible functionality and even the seamfulness of interactions with the mobile device are more important to the user and to adoption of the device than are the specifics of the interface design.

\section{Related literature}

\subsection{Mobile phone use}

Most previous literature has approached the mobile phone as a novel technology, still in its design and adoption phase. Research looking at early use is plentiful, both in relation to regular (voice) phone use and SMS use [11, 13, $21,29]$. The design-stage view also led to a plethora of research on usability, menu design and ergonomics (e.g. [17] and [30]).

A large number of studies have looked at mobile phone use patterns as related to users' everyday lives. For example, Palen et al. looked at new cell phone users' practices and their changing perception of social space [29]. Ito et al. looked at mobile phone use and functionality [13], but among teenagers, a group with different priorities and financial means than working adults. Ling, in his study of teenage use of SMS, connected text messaging to broader social practices such as "microcoordination." [22] Notably, Wilksa [41] looked at gender and "consumption styles" (such as impulsiveness, trend consciousness, technology enthusiasm, thrift, environmentalism) among young mobile phone users in Finland. Wilksa found that phone use patterns split not along gender but along consumption style. Fewer studies have looked at the personal impact of email-enabled phones, for example Mazmanian et al. [23] and Middleton and Cukier, who found extensive disruptive effects of Blackberries on users' daily lives, despite users' contentions that the devices made them more efficient, prompt and productive [24]. Finally, other studies have looked as use of specific parts of newer multifunctional phones; O'Hara et al. studied the use of video communication [28], and Karlson et al. investigated sharing practices of smart phones [15]. Kindberg et al. looked at mobile picture sharing [18], and Nylander et al. studied how phones with Internet access are being used and showed that a large portion of Internet access from mobile devices in fact takes place in situations where the user had Internet available through other means such as a PC [27].

\subsection{Potential uses of personal mobile devices}

Although the availability and therefore use of smart phones have until recently been limited, the prospective of mobile information and context-aware devices have resulted in 
numerous research studies of possible future uses of mobile personal devices in general. Sohn et al. for example studied the mobile information needs of participants and found that 30 percent never got their mobile information need satisfied [39]. Others such as Barkhuus and Dey, Khalil and Connelly, and Lederer et al. have looked at how willing people are to share sensitive information such as their location, with whom they would be willing to share this information and under what circumstances [4, 16, 21]. More recently, Poole et al. used folk theories to gain insight into public perceptions of a new and to some extent controversial mobile technology: RFID tags [32]. All these studies focus on perceptions and prejudices rather than everyday practices. A notable exception is a study of "ultra portable devices" that traced use of notebook computers [34].

In our study, we distinguish ourselves from previous work by not just singling out functions or services but looking at multi-functionality itself and its effects and affordances.

\subsection{UbiComp and HCI visions}

Bell and Dourish suggest that ubiquitous computing has already come to pass, but in a form different than that originally envisioned [5]. They highlight that Weiser's scenario lacks the concept of the "carried around device" (e.g., personal multifunctional mobile phone) and go on to describe cases in which the mobile device is used in ways that might describe the real but "messy" ubicomp. However, it has not been clear how this messiness manifests itself in more tech-savvy environments, or what this means more generally to ubicomp's vision and future. We take a closer look at that messiness here.

Norman's proposal of single-function appliances as a solution to personal computer complexity [26] is also in direct contrast with the popularity of multifunctional phones. Our data suggest that these devices are popular not in spite of their multiple functions but directly because of them. In fact, even when extra work is required to use them, the presence of multiple functions has become more important than the design of the interface used to access them.

\section{Method}

In order to understand how users integrate multifunctional mobile phones into their everyday lives, we used two different inquiry methods, semi-structured interviews as well as daily diaries over 3 weeks, for our data collection. The interviews were transcribed and analyzed together with the diary material.

\subsection{Participants}

We interviewed 21 adult (average age 37) California residents who were users of mobile phones: 13 iPhone users, four Blackberry users and four users of other multifunctional phones. The participants were recruited through personal contact, email lists and public postings. See Table 1 for participant details.

\subsection{Process}

All participants were interviewed in person (11) or via telephone (12). They responded to questions about mobile phone versus computer use, personal versus work use of the mobile device, and what they liked and did not like about the device. They gave examples of their recent use and described specific functions they used frequently. They were asked to characterize their device and their lifestyle and to discuss how well the device fit their needs. Half of the participants also kept logs of the numbers of calls, text messages, email messages sent and received on the phone each day for 3 weeks. These logs provided us with an 'in context' dataset of use, which was held against the interviews for more detailed analysis. Participants also completed daily diaries, giving examples each day of phone use for work and for personal needs, noting any unusual events,

Table 1 Study participants

\begin{tabular}{lllll}
\hline Name & Device & Age & Occupation & Gender \\
\hline Annabel & iPhone & 45 & Unemployed & F \\
Andrew & iPhone & 43 & IT manager & M \\
Bob & Blackberry & 55 & Architect & M \\
Cathy & iPhone & 34 & Consultant & F \\
Doug & Motorola Q & 32 & Systems engineer & M \\
John & iPhone & 47 & CEO of small company & M \\
Karl & iPhone & 23 & Sales manager & M \\
Mike & Blackberry & 60 & IT director & M \\
Miranda & Nokia N95 & 26 & Researcher & F \\
Monica & Blackberry & 32 & Andrew gallery manager & F \\
Oliver & iPhone & 32 & Animation tech director & M \\
Patty & iPhone & 29 & Finance manager & F \\
Paul & Blackberry & 40 & Help desk manager & M \\
Peter & iPhone & 35 & Software consultant & M \\
Rebecca & iPhone & 24 & Sysadmin & F \\
Sheila & iPhone & 49 & Writer & F \\
Sidney & iPhone & 35 & Graduate student & M \\
Tasha & LG & 32 & Teacher & F \\
Terence & iPhone & 35 & Unix Sysadmin & M \\
Theo & Palm Treo & 53 & Clinical psychologist & M \\
Tina & iPhone & 41 & Healthcare worker & F \\
\hline Nane & Phenciant &
\end{tabular}

Names have been changed to protect participant anonymity 
and giving the ratio of their email use on the device versus email use on an ordinary (desk- or laptop) computer. They described the day's activities, discussed how their phone use related to those activities and explained specific triggers for phone use.

\subsection{Analysis}

We collected the electronically entered logs/diaries and transcribed recorded in person and telephone interviews. Our analysis traced general practices from a self-reported perspective rather than from a direct observational perspective. Logs were used to verify self-reports of frequency of different types of activity and generally indicated a high degree of accuracy; however, we focused on participants' own perception of their practices as much as their actual use. Our analysis followed many aspects of Grounded Theory [10], such as coding of data and establishing relevant categories for these. The categorization enabled us to flesh out motives and objectives of the participants in terms of their detailed use of mobile phones.

\section{Findings}

\subsection{Adjusting use to situation and recipient}

Even with similar devices, and even when using the same applications or functions, participants each used their smart phone in their own unique way. They particularly adjusted use to the situation and to the recipient of specific communication.

For example, nineteen of the participants texted on a regular basis (daily or at least weekly), but for very different reasons and in different contexts. John, a father of four, used text messages as reminders to his colleagues and texted daily with his teenage daughters. Sidney explained how he had come late into the 'texting game': "[...] since I'm gay, a lot of my friends are like, 'come on, there are no gay men who don't text'... it's the universe of junior high kids and gay men. But once I came to it I realized how effective it was." Sheila texted her spouse to "feel closer" when he was at work. Andrew exchanged text messages with his spouse daily to determine when each would arrive at home. Terence used a text message rather than an email when he knew "that my target audience is not in front of a computer." Annabel reported texting "if I need to get in contact with a friend, like if she's in a meeting or something and I don't want to call or send an email [because] it's easier for her to check her text messages." Most participants alternated between SMS texting, Blackberry's proprietary text system, instant messaging and email, depending on the situation and people involved.
Media richness theory predicts that different communication media are chosen on the characteristics of each communication channel [9]. For our participants, it was more relevant that others communicated with them using diverse methods; having these methods united on the phone allowed them to be reachable in different ways by different individuals and to respond in a manner appropriate to their and the recipient's circumstance. Frequently, reply mechanism was determined by the initiator's initial choice of mechanism (that is, a voice message received a voice response), though we did see occasional evidence of selection based specifically on communication channel characteristics; for example, some users reported responding to (notably) work-related text messages with voice calls in order to "obtain more information about the situation." But the overriding reported characteristics for initiated communication method were convenience, pragmatics and urgency. For example, Terence chose text messaging when he needed to reach someone for a work emergency regardless of where they were. Like the vast majority of our participants, Andrew sent less email from his phone than from his computer and explained that "it depends on my situation and how soon I'll be getting in front of my computer again as to whether I'll shoot email from it or not." Tina, a health care worker, frequently had to contact residents who might be working with patients and opted to use text messaging as it was less obtrusive. The many choices of method suited the participants. Paul, a Blackberry user, said: “... [W]ith the job I do in customer service, we're on call, [...] and people either don't think to email me or don't think to call. So I have both options." Bob told us that "some emails requested a voice, a text, or an email return message." Flexibility was paramount.

\subsection{Location-based services}

Location-based services are slowly taking shape on commercial mobile devices. Many applications for the iPhone are able to use the device's current position (determined through GPS, visible wireless networks or triangulation between cell towers); however, at the present time, thirdparty applications cannot run in the background, meaning that actions cannot be triggered by location-that is, automatically started when the device find itself in a specified position. This makes friend-finder applications such as Loopt (www.loopt.com), Mologogo (www. mologogo.com) and Connecto [2] much less practical, as the user's location is only updated when he/she accesses the application (as two of the participants also pointed out). These participants had downloaded Loopt for the iPhone but did not use it. However, we found that use of locationbased services did not rely on passive location sensing, and that users were happy to input information regarding their 
current and future location in exchange for what they considered highly valuable services. Instead of automatically triggering behavior in the phone, location information was used by our participants to receive locally relevant information, such as the nearest restaurant or ATM (of a specific bank), or locally-available environmentallyfriendly seafood. When location was not automatically detected, services utilized the user's own proactive specification of their present locale. The difference in granularity needed for each application sometimes made selfdefinition more appropriate. Self-definition of location also made sense in situations where users were planning to go somewhere, as location-based applications cannot anticipate a future location.

One of the most useful 'location-based services' was the map, available on all the smart phones in some form. Whereas the iPhone has Google Maps as a native application, most other devices rely on map applications via the Internet. Blackberries vary depending on the model (newer models have native maps). Three of the four Blackberry users had Blackberries with native map applications, which work similarly to that on the iPhone. For all users, maps were a favorite functionality. As Monica explains: "I don't have GPS in my car so it is really great, cause I can just figure out where I'm going and especially if I' $m$ going to a screening or an opening, after work and instead of printing out paper descriptions from home, I just plug it in [...], I use that probably six, seven times a week." Rebecca enjoyed checking the traffic and admits that this function is probably the one she uses the most on her iPhone. Sidney used the map-based directions for biking: "You can pretty much decipher biking directions from the driving directions given." Tina was particularly fond of the ability to search for generic stores, such as 'restaurant' and 'bar' on the map, and used this frequently. Annabel used hers because "I get lost a lot."

\subsection{Mixing and matching functionalities}

Our participants mixed and matched functionalities in ways the designers may not have imagined, but which well fit their particular needs and lifestyles. Andrew spends much of his time on public transit, and the timing of trains and buses is particularly important to him. In consequence, he chose to "compare sources" about transit information, using multiple Web sites in conjunction with a Twitter feed of next-train information to determine when trains and buses would arrive and leave. Terence had loaded a number of music applications that he used together for music creation, including several which generated alternate chords and chord positions.

Communication encompassed a range of different phonebased modalities-voice, text, Blackberry messenger, instant messenger and email. As we argued in the introduction, the combination of these different communication methods proved particularly valuable. Terence, who had to participate in regular conference calls, often received text messages from his wife during those calls. Annabel described simultaneously sending IM and text messages. Andrew expected his spouse to see both his Twitter messages and his texts.

Searching for information on the Web was a highly desirable function. Four people explicitly stated that having Internet on the go was the main reason they had acquired a multifunctional mobile phone. Again, though, users searched in different ways. John and Doug had bookmarks pointing to news Web sites and information services such as Wikipedia. Many iPhone users reported searching for phone numbers and addresses using the built-in Google search, but Karl and Peter preferred the Google Web site. Rebecca liked to look up words in etymonline.com. Other iPhone users had downloaded applications such as Yelp and Urban Spoon to search specifically for restaurant and store information coupled with reviews.

Participants described many cases of application combining and overlap. Oliver had an elaborate setup where he used the application BrightKite to update his 'status'; this would initialize a chain reaction where his Twitter would be updated and a Twitter plug-in would then update his Facebook status. Miranda took photos with her camera and uploaded them to Flickr. Cathy felt an earthquake occur, used Web sites to get more information and then Twittered about her experience. Annabel used the Urban Spoon application to select a restaurant, Google to find directions, and the GPS and map functions to assist her when the directions failed and she got lost.

Users found creative ways to adapt less-suitable technology to their own circumstances by mixing applications. Theo used his device as a broadband modem for his laptop when needed. Miranda had her voice mail messages send through Callwaves, a service which emailed and texted her when she had voice mail. She would then connect to the Callwaves Web site at her leisure to listen to the messages.

\subsection{Adding features, ignoring others}

The iPhone users who we studied had downloaded dozens of applications from Apple's built-in 'AppStore'. The applications that participants selected were diverse in aim and functionality, from games and social network applications to currency converters, timers and even a bubble wrap popper application.

User-specified downloadable applications for smart phones are a recent option, yet directly contradict the notion of single-function devices and, indeed, of the seamless interaction of user with device, since the users 
had to select appropriate functionality and deliberately obtain it for their phones. They did not see this as an inconvenience, but, notably, they also did not express seeing it as an advantage. It was simply an expected part of the way they configured the device to their particular practices, desires and needs. Terence had downloaded several weather applications, "just because I like to know what it's, you know, going to be temperature-wise."

Interestingly, ubicomp research has yet to consider the value of smaller and much more personal incremental services such as banking, calorie counters or even using your phone as a spirit level. Yet the collection of applications made the participants' smart phones far richer tools and embodied the notion of their device as universally useful. Oliver, for example, explained that he did not use his phone more after the AppStore made third-party applications available but used it more "succinctly". It is not that there were 'unfulfilled needs' for the services that the applications supported, but the possibility for adding productive and recreational functionality alike made the device seem ubiquitously integrated into participants' lives.

The ability to shuffle a diversity of applications, with new applications released frequently, allowed users to experiment. Terence, for example, reported downloading Skype, a spirit level, and a periodic table of the elementsnone of which he used after the initial experimentation. Cathy "surfed Apple's Web apps and found Mind Dojo. Tried that out...played with a few more Apple Web apps: tried out a Skype access app, thincloud's Twitter app, a food finder near a zip code app, a London Tube status app, and used Mind Dojo again." While the number of applications that users returned to and regularly used was small, each application still offered some interest if not much utility. Whatever the functionality of the apps, then, the store also provided entertainment value in the variety of ever-changing applications that could be tested.

Nonetheless, participants did not tend to characterize their phones as entertainment or 'fun' devices in particular. "A Swiss Army knife," said Terence, echoing the "all of the above" responses of many other participants. Peter said he liked his device because of "the almost computer-like features that it has [...] Sort of a mini-computer, you can browse, you can do email on it, you can go to map..." The multiple functions were valuable in and of themselves and not just for their value as entertainment.

Participants ignored features that did not work, did not work well or did not suit their needs. Because Google's Web site had disabled the pinch-zoom function of the iPhone, Terence, who has poor vision, avoided the site. Theo said the camera on his Treo was "mediocre," so he did not use it.

In the United States, the Blackberry was the first mobile email device that enabled people to send and receive email from 'everywhere' [24], so it is unsurprising that in our study, Blackberry users, more than other users, perceived email as the main function of their device. However, two of the Blackberry users had turned off the automatic notification setting and had to explicitly check for email themselves.

Despite having Web surfing available as an easy-to-use function, many users reported not making use of the ability. Mike, a Blackberry user, said he had never used the Internet except once or twice as a novelty. Annabel called her iPhone "pretty much a necessity" but did not use the browser because "the screen is too small."

Several people did not use the music player function of their phone. In Cathy's instance, this was because she already had an iPod nano setup in her car and it was lighter in weight for running. In Oliver's case, because he was a music and video enthusiast, he preferred to have his highstorage-capacity video iPod with him for music instead.

\subsection{Use in everyday life}

\subsubsection{Sharing phones}

Our participants integrated their mobile device use thoroughly into their everyday lives. To some degree, they shared their devices with other humans in their vicinity. Terence reported that he and his wife both used his iPhone to make use of the Facebook utility. John, Peter and Oliver had downloaded games specifically to share their iPhones with their children. Terence downloaded some movies for his toddler son "for when we're traveling and the kid decides he wants to freak out." The phone entered into personal interactions in a variety of ways. Speaking for a number of participants who said they used the search functions on their phones during arguments, Miranda admitted that "sometimes during a conversation I wouldI would look up info or resolve a debate with Wikipedia."

Participants used their devices in ways that were convenient to their circumstances. Most of the participants saw the email on their phones as useful for receiving email messages, writing short notes back only in time-critical incidents, rather than for composing long replies. Terence said, "I don't know that there would be anything in particular that would make me respond [to email] via the phone except urgency." Andrew told us that he would use the device to send email "if it's, one, a critical message that needs to get out right then and there, or if it's a very short, you know, a couple-word message."

\subsubsection{Communication via online social networks}

Apart from the obvious use of direct communication, application-based social networking and social 
communication was also prominent, especially among participants who had rich social lives. Six participants were heavy users of social networking applications on their phones, some using mobile applications and others using the Web versions through their mobile phone. Four iPhone users stated that the Facebook application was the first one they downloaded when the AppStore opened and that they used it every day. (The Facebook application is ranked as the third most popular application in the AppStore [7].) For Cathy, mobile access to social networking was one of the most important reasons she had acquired an iPhone. Monica expressed that her Facebook application "feeds the addiction" and John admitted to "scoping out what folks were doing" before going to bed on most days. Peter took photos of his children at the mall and mailed them to a group of his friends. Andrew reported reliance on his Twitter feed, both for social updates and for receipt of critical news and information that affected his commute. This information would then affect what he wrote in his Twitter updates, which could in turn be read by his social network.

\subsubsection{Work/life balance}

Often a topic of debate in modern Western society, participants' work life blended into their social life, a factor perhaps caused by mobile communication devices and home email. This 'spillover' and constant work expectations that have been emphasized in the media and to some extent in previous research $[24,25]$ was not seen as much of a problem by most participants.

Still, one distinction between the participants was whether and how they allowed their social life and work life to collide. Although most participants were able to construct a home-work boundary [25], some chose not to and allowed the two to integrate. Participants who worked as consultants or mobile workers or had 'transitional' jobs such as Sidney (a graduate student) and Miranda (a freelance researcher) were more likely to report using their device for a mix of personal and work purposes. Andrew, who supervised employees in various states and countries and telecommuted frequently, reported often making social engagements with a colleague while on a work phone call. This corresponds well to Nippert-Eng's description of the different opportunities for separating home from work, which different work cultures afford [25]. The smart phone provided participants with an opportunity to integrate the two worlds easily, but could also be employed to separate them.

The remaining participants either used the phone for exclusively personal purposes or were particular about separating work from leisure, sometimes through technical setup, other times through behavior. Oliver, an iPhone user, said he was "not much of an email guy," limiting email to work-related communication. His iPhone was a personal device, so he did not use email on it frequently, but used it at home instead of his computer in order to 'control' work. If he went to the computer to check his email, he feared he would be distracted by work located on the computer; with the iPhone, he could check if there was anything timepressing without getting stuck the rest of the evening on the computer. He had only given his phone number to a select set of colleagues, expecting them to call only rarely. Theo, on the other hand, explicitly defined his phone as a work device and avoided using it for personal purposes.

For many, therefore, the separation of work from leisure was not always explicit, but despite previous research suggesting otherwise [24,36], we did not hear many participants express the 'always available' characteristic of an email-enabled phone as a problem. They enjoyed the ability to surf for friends' new status updates during 'hourlong boring meetings' as much as they enjoyed the ability to answer an important work email at $11 \mathrm{p}$.m. In fact, rather than complaining about the intersection of work and home life, participants felt they could adapt the device to allow this intersection to be comfortably negotiated. Several participants used their iPhones in bed, especially to answer work-related, sometimes-automated text messages (frequently referred to as "pages" by some of our users). Terence used his phone "where it's convenient, right? Like I'm on call a lot, so... my iPhone is also my pager, so if I get paged, it's really neat for me to not have to get up, get out of bed, walk down the hall, sit on the you know, turn on the monitor etc.- I flip over to the email app [...] and I make the decision as to whether or not I need to, you know, get up." Andrew said that now that he had his smart phone, he had a "much better demarcation" between work and private life.

\subsection{Adaptation, compromise and perception of nuisance}

Compromise is not a new notion in terms of technology adoption; related is Herbert Simon's concept of "satisficing" [38], which describes how individuals compromise rather than searching for the exactly optimum solution to their problems. Other scholars have talked about technological 'make-do', where users live with less than adequate technology by putting considerable effort into getting what they have to work [12].

Our concept of compromising seeks to include a broad spectrum of these types of practices-where technology is stretched and compromised to approximate the diversity of situations and practices that participants find they have. Technology is seldom perfect; it nearly always fails in some way, misses features or has absences or problems. 
Smart phone use-while it provides much in the way of new functionality-is also an exercise in overcoming absences.

Mike, for example, felt that a drawback of his Blackberry was that it did not have voice recognition for dialing. He said that this missing feature made him use his Blackberry less for phone calls, since he could not easily dial a number while driving. Rebecca and Patty did not get good reception at their home and office, but had opted for the iPhone (locked to AT\&T) anyway. Participants also made compromises because of budget constraints and the details of their service plans; Cathy did not text her friends as much as she used to, because her iPhone did not have a text plan and she had to pay extra for it as compared to a phone call, and John was not willing to pay for applications in the App Store, but was "trying to see how enriched [he could] become on freeware."

But all of our users liked their smart phones, and most were reluctant to list negative aspects. If they had initially found a functionality to be difficult or irrelevant to use, they left it alone or chose to perform the activity on a regular computer. They did not express these cases as a problem. Only when pressed were they were able to identify areas that could be improved. Mike cited the downside of email messages sent from a Blackberry-that the device does not lend itself to polished composition: “...my boss just kinda sends misspellings and things, just like that. And he is so cryptic you don't really know what he means."

Users did not always find missing functionality to be a nuisance, often because their actual needs were different than those anticipated. Despite longing for such an app, after the AppStore had made instant message tools available, Cathy admitted she had not ended up using these apps. Instead, she used a Twitter app and occasionally the iPhone Facebook application, because her social sphere turned out to be on Twitter rather than IM. When arguing for using a particular social network, Oliver stated that "since Dodgeball was dead," he had migrated over to other networking platforms. Terence did not mind the lack of cut and paste functions on the iPhone (recently added). "I use this thing every day, and I have yet to cut and pastemaybe twice," he said, suggesting that complainers might be "lazy." Non-iPhone users generally had to go through a special setup to be able to use mobile Web (Doug for example had installed the mobile Opera browser), so some used the Web extremely rarely. However, none of the noniPhone users expressed any issues over their 'inability' to access the Web in mobile situations. Participants whose phones lacked location tracking ability did not request this functionality and, even in relation to social networking, did not express a desire to be able to broadcast their location automatically.
Sometimes, location set limits on the possible uses of the device. When on a subway train underground, Andrew did not have access to his Web and Twitter feeds; during these times, he read e-books using his Kindle application. Our users described this type of "service interruption" as an advantage, as they were forced to take a break from the threat of a work-related text message or call.

Notably, our participants were still willing to use applications that had flaws. Several participants talked about 'buggy' programs that would often quit without notice. Peter and Miranda used the camera "a lot" but described it as underwhelming. Annabel complained that she "missed a lot of calls" because the iPhone ring was too soft even on its highest settings, but nonetheless said she loved her phone and would not be without it.

One participant's compromise was another's favored feature. While Tina was very excited about the camera on her iPhone and particularly by how easily it synced with her computer, and Miranda and Terence were enthusiastic about the ability to take photos and post them immediately to Facebook or Flickr, others said the camera or uploading process was a feature they wished they could improve due to its low resolution.

The participants did not view the compromises as obstacles, however-merely as an adjustment. Doug referred to some factors as "tradeoffs" but also described the phone as "necessary." This compromising of behavior and functionality essentially exposed the seams of the technology, similar to the exploration of 'seamfulness' in ubicomp [6]. These seams were negotiated with relative ease, and as has been found in previous research, participants had learned to work around them [3]. The participants' compromises also illustrated how the 'messiness' of ubicomp infrastructure [5] is handled through adjustment of both the technology and practices.

Importantly, participants did not describe their action as "messy" or effortful in any way. Though one might use Google maps, another a Web site with directions, another the built-in GPS guide, another a combination, they were not generally conscious of choosing one technological feature over another or of adapting their behavior to the device. Even participants who described elaborate steps required to achieve some goal through the use of multiple applications were offering these as examples of the flexibility of their device and did not complain about them.

\section{Discussion}

Our results illustrate how users of multifunctional phones interpret the technology in use, a characteristic emphasized in theories of social construction. We focused on how users view their phone both through the expectations they had of 
their particular device and through their particular needs. In fact, only a few functions were used ubiquitously (perhaps none universally save voice communication-possibly the only reason these mobile devices are still labeled 'phones').

\subsection{Making it their own}

By collecting functionality together in one platform, each mobile phone acts as a portfolio in the hands of each particular user, with different functions used and others ignored. Several participants referred to their phones as "Swiss Army knives" and others described them as "a loyal dog, doing just what I ask him to do." Although an outside view allows the perception that no phone perfectly fit its user, the participants generally viewed their phones as well suited to their needs. This suggests that people have successfully adopted the technology and 'made it their own' as social construction theories propose [31]. And perhaps this is unsurprising. As Ramachandran [33] proposes for the visual areas of the brain, it seems likely that humans solve problems using a 'bag of tricks' approachfinding the right combination of available tools to fit the situation rather than seeking the perfect package. Our users clearly did so with the smart phones, possibly because that behavior is a good match for natural brain function.

Our users adapted to the heterogenous world of other users, as well. Lack of universality, or lack of intercompatibility, shaped use and is probably one reason that broadly used and multi-platforms Web-based services such as Facebook, BrightKite and Twitter were popular among our participants (only four did not use at least one of these social networks) and why people went through elaborate setups to use these applications through their phone (some people would use SMS-based Twitter to update their Facebook status, others had downloaded a Facebook application to their Blackberry, etc.). We only witnessed one platform-specific behavior: the participant who used Blackberry's internal message system. Interaction with one's social network and humans in the immediate vicinity was important, and users adapted their devices to fit that priority, adding and using applications as appropriate.

\subsection{Seams and smoothness}

The work that participants described they did to use their phone was not insignificant, involving active configuring, selecting, adding and subtracting. Participants had to plug in the device to update calendars and transfer photos; when that infrastructure broke, they would cease to use it. Tina, whose roommate had lost his computer and consequently synced his iPhone with her laptop, stopped using her calendar because she could not separate her appointments from her roommate's. Karl had yet not figured out how to set up his email on his iPhone 2 months after acquiring it, and so he did not use email on his phone. In contrast to many future proposals of ubicomp technology $[1,19,40$, 41], the phones had no sensors that would detect if it was night and the owner asleep, so participants had to manually set them to silent in order not to be awakened by friends and family in other time zones. Many settings had to be made by hand, such as options for 'push' or 'pull' email and logging onto wireless networks. Smart phones-like other technologies in our lives-need to be tended to, maintained, kept alive, charged and cared for. As Sherry et al. point out, technology is in need of a "human layer" [37].

Despite that, users described their devices as adding to the smoothness of their lives. This may be because seamlessness was present-in the form of the integration of many functions within a single device. The smart phone created the option of taking entertainment, information resources, email and other computer-based applications with them, in the car, when shopping, in the café or while waiting for a bus. Many of these functions were available before the advent of the smart phone-as individual devices, as with an MP3 player, or in other formats, as with books or printed maps. The phones both folded many applications into one and added features; for example, when plans changed, they could easily adjust their route, verify the address of a destination, or check tardy friends' whereabouts on Twitter.

Still, the multifunctional phone is far from the notion of a "disappearing" computer. If we can corrupt slightly Chalmer's concept of seamfulness [6] (based on Weiser's own musings), these actual uses of ubicomp-in the form of smart phones-are about dealing with, manipulating and even taking advantage of the unintended seams in technology. When Norman suggested that computing appliances would provide us with "invisible computing," it was through ease of use and simplicity of function that this was to be reached [26]. To our participants, their mobile phone was in no way invisible [35]. It was always there, right in front of them-two participants called it a "leash." But it still constituted a connection to all realms of their lives, negotiating work life, social relations, etc., all in the user's own idiosyncratic fashion. Email was particularly seamful in use. The seams of sporadic network connection, keyboard and lack of same, etc. are all exposed constantly to the users. But users negotiated these seams, using their email through the phone when wireless access would be complicated through a client's secured network or using the landline when the phone provider could not reach their cubicle. Participants even used seams themselves to control their behavior, such as the participant who only checked his email on the mobile device at night, to stay away from the work that was on the regular computer. Transparency 
and seamlessness is not attained in smooth use of the functions on the users' phones, but instead in the combining of everyday applications and tasks on a single mobile platform and in the possibilities offered by a portfolio of services.

\subsection{Design and the prediction of use}

A primary principle of user-centered design is to understand "users and their needs," a process which starts with watching users at work and understanding what they want to do and how they want to do it [26]. The variety of ways in which our participants approached a task makes design using this principle a challenge. The finding that participants negotiated functionality to fit into their needs (using email drafts synced through IMAP as to-do lists, jailbreaking their iPhone to install particular programs) or adapted their needs to the possibilities of the device (checking information while on the bus, but reading ebooks when on subway train) shows how difficult it is to predict actual use of technologies. Even the fact that the map tool, possibly designed with a driver of an automobile in mind, was used by pedestrians, commuter train users and bicyclists suggests the magnitude of such an approach. The multifunctional phone is a multifaceted object that allows the user to adjust their perception of both a task and a technology fluidly. Studies looking at how people behave in mobile environments mostly approach the proposed technology as homogeneous and stable. It has been demonstrated that how people say they will react is very different from how they actually do act in relation to technology [14], and there are multiple factors at play when users are confronted with a real situation. It was interesting to see that users are willing to compromise to such great extent that they use different communication means if one is too expensive, and that they eschew specific social network applications, regardless of perceived features or attractions, because their friends are on another. These examples highlight the complications of predicting how users will act, what they want and in what way they will need technology, and question the value of contextually adjusting applications.

\section{Conclusion}

Our study lends empirical support to the work of Rogers [34] and Bell and Dourish [5], showing us an active user negotiating a messy interface in relative comfort. We further see that smart phones embody seamlessness and invisibility only to the level of task transference between platforms and perhaps between applications, but that the platforms themselves and the individual practices of use are characterized by seamfulness, and we see users taking advantage of those seams.

Finally, we have noted how the individuation of use facilitated by this technology makes prediction of use challenging and suggest this requires a novel approach to interface design. In fact, in a multifunction environment with the ability to adapt, add and remove functions, the interface itself becomes less important. Our users had a variety of phones with different interfaces, but their use varied by individual lifestyle, environment, and personal preference and need. The unique characteristics of the multifunction phone were in enabling the ability to select functionality and to blend it in unique ways. We saw Rogers' "proactive user" taking part in "engaged living, where technology is designed to enable people to do what they want, need or never even considered before by acting in and upon the environment." [35] When provided with a rich portfolio of possibilities, our engaged users were able to adapt their smart phones to work for them-in their own ways-and found them a good fit.

Because of this, we suggest designers will need to look beyond the interface and applicability of a mobile device or any individual app running on it and to direct their focus on interoperability and middleware that will allow tools to be maximally "snap-on." Our research suggests the power of the ability to mix, match and interconnect individual apps was in large part what has made the smart phone so successful as a ubicomp device. Enhancement of this functionality may be the important direction that distinguishes successful mobile phones in the future. The ultimate ubiquitous device may in fact be the hand-held equivalent of classic children's toys such as Tinkertoys ${ }^{\circledR}$ or Erector ${ }^{\circledR}$ sets-where the sum (and assemblability) of the parts, in the end, is more important than the whole.

Acknowledgments We thank the participants for their time.

Open Access This article is distributed under the terms of the Creative Commons Attribution Noncommercial License which permits any noncommercial use, distribution, and reproduction in any medium, provided the original author(s) and source are credited.

\section{References}

1. Abowd G, Mynatt E (2000) Charting past, present, and future research in ubiquitous computing. ACM Trans Comput Hum Interact (TOCHI) 7(1):29-58

2. Barkhuus L, Brown B, Bell M, Sherwood S, Hall M, Chalmers M (2008) From awareness to repartee: sharing location within social groups. In: Proceedings of CHI 2008, ACM Press, New York, pp 497-506

3. Barkhuus L, Chalmers M, Tennent P, Bell M, Hall M, Sherwood S, Brown B (2005) Picking pockets on the lawn: the development of tactics and strategies in a mobile game, In: Proceedings of Ubicomp, Springer, pp 358-374 
4. Barkhuus L, Dey A (2003) Location-based services for mobile telephony: a study of users' privacy concerns. In: Proceedings of Interact 2003, pp 207-212

5. Bell G, Dourish P (2007) Yesterday's tomorrows: notes on ubiquitous computing's dominant vision. Personal Ubiquitous Computing 11(2):133-143

6. Chalmers M, Galani A (2004) Seamful Interweaving: Heterogeneity in the theory and design of interactive systems. In: Proceedings of DIS 2004, ACM Press, pp 243-252

7. ComScore. Tapulous' Tap Tap Revenge Has Been Downloaded by 1 our of 3 iTunes Application Users. http://www.comscore. com/press/release.asp?press $=2768$

8. Cowan L, Griswold WG, Barkhuus L, Hollan JD (2010) Engaging the periphery for visual communication on mobile phones. In: Proceedings of the 43rd IEEE Hawaii international conference on systems sciences (HICSS 2010), Hawaii

9. El-Shinnawy M, Markus ML (1997) The poverty of media richness theory: explaining people's choice of electronic mail vs voice mail. Int J Hum Comput Stud 46(4):443-468

10. Glaser BG, Strauss AL (1967) The discovery of grounded theory. Aldine, Chicago

11. Grinter R, Eldridge M (2003) Wan2tlk?: everyday text messaging. In: Proceedings of CHI '03. ACM, New York, pp 441-448

12. Hughes, JA, Sharrock WW, Rodden T, O'Brien J, Rouncefield M, Calvey D(1994) Perspectives on the social organization of work, field studies and CSCW, COMIC Deliverable 2.2, pp 129-160, Esprit Basic research Project 6225: Lancaster University

13. Ito M, Okabe D, Matsuda M (eds) (2005) Personal, portable, pedestrian: mobile phones in Japanese life. MIT Press, Cambridge

14. Jensen C, Potts C, Jensen C (2005) Privacy practices of internet users: self-reports versus observed behavior. Int J Hum Comput Stud 63(1-2):203-227

15. Karlson AK, Brush AB, Schechter S (2009) Can i borrow your phone?: Understanding concerns when sharing mobile phones. In: Proceedings of CHI '09. ACM, New York, pp 1647-1650

16. Khalil A, Connelly K (2006) Context-aware telephony: privacy preferences and sharing patterns. In: Proceedings of CSCW '06, ACM Press, New York, pp 469-478

17. Kiljander H, Lindholm C, Keinonen T (2003) Mobile usability. McGraw-Hill, New York

18. Kindberg T, Spasojevic M, Fleck R, Sellen A (2005) I saw this and thought of you: some social uses of camera phones. In: Proceedings of CHI'05. ACM, New York, pp 1545-1548

19. Lambourne R, Feiz K, Rigot B (1997) Social trends and product opportunities: philips vision of the future project. Report accessed from: http://sigchi.org/chi97/proceedings/briefing/rl.htm

20. Landay JA, Joseph AD, Reynolds F (2009) Guest editors' introduction: smarter phones. Pervasive Comput 8(2):12-13 IEEE

21. Lederer S, Mankoff J, Dey AK (2003) who wants to know what when? Privacy preference determinants in ubiquitous computing. In: CHI '03 extended abstracts. ACM, New York, pp 724-725

22. Ling R (2004) The mobile connection: the cell phone's impact on society. Morgan Kaufmann, Boston
23. Mazmanian M, Yates J, Orlikowski W (2006) Ubiquitous email: individual experiences and organizational consequences of Blackberry use. In: Proceedings of the 65th annual meeting of the academy of management. Atlanta, GA

24. Middleton C, Cukier W (2006) Is mobile email functional or dysfunctional? Two perspectives on mobile email usage. Eur J Inf Syst 15(3):252-260

25. Nippert-Eng CE (1995) Home and work-negotiating boundaries through everyday life. The University of Chicago Press, Chicago

26. Norman D (1999) The invisible computer. MIT Press, Cambridge

27. Nylander S, Lundquist T, Brännström A (2009) At home and with computer access: why and where people use cell phones to access the internet. In: Proceedings of CHI '09. ACM Press, New York, pp 1639-1642

28. O'Hara K, Mitchell AS, Vorbau A (2007) Consuming video on mobile devices. In: Proceedings of CHI '07. ACM, New York, pp 857-866

29. Palen L, Salzman M, Youngs E (2000) Going wireless: behavior $\&$ practice of new mobile users. In: Proceedings of CSCW, ACM (2000), NY, pp 201-210

30. Palen L, Salzman M (2002) Beyond the handset: designing for wireless communication usability. ACM ToCHI, 9(2):125-151

31. Poole ES, Le Dantec CA, Eagan JR, Edwards WK (2008) Reflecting on the invisible: understanding end-user perceptions of ubiquitous computing. In: Proceedings of UbiComp '08, vol 344. ACM, New York, pp 192-201

32. Ramachandran VS (1993) Interactions between motion, depth, color and form: the utilitarian theory of perception. In: Blakemore C (ed) Vision: coding and efficiency. Cambridge University Press, Cambridge

33. Rattenbury T, Nafus D, Anderson K (2008) Plastic: a metaphor for integrated technologies. In: Proceedings of UbiComp '08, vol 344. ACM, New York, pp 232-241

34. Rogers Y (2006) Moving on from Weiser's vision of calm computing: engaging UbiComp experiences. In: Proceedings of UbiComp 2005. Springer, NY, pp 404-421

35. Schlosser FK (2002) So, how do people really use their handheld devices? An interactive study of wireless technology use. J Organ Behav 23:401-423 John Wiley and Sons

36. Sherry J, Mainwaring S, Burrell J, Beckwith R, Salvador T (2004) 'This all together, hon?' UbiComp in non-office work environments. In: Proceedings of UbiComp 2004. Springer, NY, pp 179-195

37. Simon H (1969) The Sciences of the artificial, 1st edn. MIT Press, Cambridge

38. Sohn T, Li KA, Griswold WG, Hollan JD (2008) A diary study of mobile information needs. In: Proceeding of CHI '08. ACM, New York, pp 433-442

39. Want R, Pering T, Borriollo G, Farkas K (2002) Disappearing Hardware. IEEE Pervasive. January-March 2002, pp 36-47. IEEE

40. Weiser M (1991) The Computer for the 21st century. Sci Am 265(3):94-104

41. Wilksa T-A (2003) Mobile phone use as part of young people's consumption styles. J Consum Policy 26(4):441-463 